Article

\title{
Epoxidation of alkenes efficiently catalyzed by Mo salen supported on surface-modified halloysite nanotubes
}

\author{
Yu Long, Bing Yuan, Jiantai Ma* \\ State Key Laboratory of Applied Organic Chemistry and College of Chemistry and Chemical Engineering, Lanzhou University, Lanzhou 730000, Gansu, \\ China
}

A R T I C L E I N F O

Article history:

Received 13 September 2014

Accepted 3 November 2014

Published 20 March 2015

\section{Keywords:}

Salen molybdenum

Alkene epoxidation

Halloysite nanotube

Surface modification

High-efficiency catalyst

\begin{abstract}
A B S T R A C T
Halloysite-nanotube-supported Mo salen (HNTs-Mo-SL) catalysts were successfully prepared using a facile chemical surface modification and self-assembly method. The morphologies, sizes, structure, and dispersion of the as-prepared catalysts were investigated by transmission electron microscopy, $\mathrm{X}$-ray diffraction, and Fourier-transform infrared, inductively coupled plasma, and X-ray photoelectron spectroscopy, which confirmed the existence of the Mo salen structure and successful synthesis of the HNTs-Mo-SL catalyst. The immobilized catalyst was found to be highly reactive in the epoxidation of a wide range of alkenes, including linear, cyclic, and aromatic alkenes. The immobilized catalyst exhibited a higher catalytic activity for alkene epoxidation than homogeneous Mo. In contrast experiments, it was determined that the salen structure played an important role in immobilizing $\mathrm{MoO}\left(\mathrm{O}_{2}\right)_{2}(\mathrm{DMF})_{2}$ and improving the conversion and efficiency of alkene epoxidation, which could not be obtained using other ligands, such as the $\mathrm{N}$ atom as a single ligand. Furthermore, the bonding between Mo and the salen ligands and the possible mechanism of alkene epoxidation catalyzed by the catalyst were determined. The catalyst could be reused several times without significant loss of catalytic activity. Given that halloysite nanotubes are cheap and easy to obtain, this catalyst offers a novel alternative for the rational design of catalysts with desired features.
\end{abstract}

(C) 2015, Dalian Institute of Chemical Physics, Chinese Academy of Sciences. Published by Elsevier B.V. All rights reserved.

\section{Introduction}

The epoxidation of alkenes is one of the most widely studied reactions in organic chemistry. The resultant epoxides are important intermediates in organic synthesis and essential precursors in the synthesis of various important substances, such as plasticizers, perfumes, and epoxy resins. Catalyzing these epoxidation reactions by transition metal complexes has attracted much attention [1-5]. A number of soluble Mo complexes with different ligands have been synthesized and used as homogeneous catalysts for the epoxidation of various alkenes [6,7]. However, homogeneous catalysts have some industrial problems, such as deposition on the reactor wall and difficulty in separation and recovery of the catalysts from the reaction products. One way to overcome these problems is to immobilize homogeneous catalysts on solid supports.

In recent years, various types of supported catalysts have been reported in organic transformations. Many approaches have been used to load Mo complexes on different supports, such as silica [8-12], modified MCM-41 [13-16], zeolites $[17,18]$, and multi-wall carbon nanotubes (MWNTs) $[19,20]$, to obtain heterogeneous catalysts. However, much cheaper clay minerals have not been reported as supports for Mo complexes. Clay minerals are attractive inorganic hosts for functional inorganic-organic hybrids because of their swelling properties and charged surfaces, which can be easily modified. Clays have

\footnotetext{
* Corresponding author. Tel: +86-931-8912577; Fax: +86-931-8912882; E-mail: majiantai@lzu.edu.cn 
been successfully used in different fields, even as vectors for delivery of DNA to cells [21-23]. As a naturally abundant clay, halloysite nanotubes ( $\mathrm{HNTs}, \mathrm{Al}_{2} \mathrm{Si}_{2} \mathrm{O}_{5}(\mathrm{OH})_{4} \cdot 2 \mathrm{H}_{2} \mathrm{O}$ ) have a tubular structure similar to that of MWNTs, and they are cheap, non-toxic, and biocompatible. The tubular structure of HNTs is composed of one silica sheet with one alumina sheet on each silicate layer, and they have a diameter of $50 \mathrm{~nm}$ and a lumen of $15 \mathrm{~nm}$ [23]. HNTs have been used in various fields, such as nanocontainers for active anticorrosion coatings [28-31] and supports for catalysts in different types of reactions [32-36], and have useful structural properties [24-27].

Herein, we report the synthesis of Mo catalysts on modified HNT supports. To the best of our knowledge, the synthesis of Mo salen (Mo-SL) supported on surface-modified HNTs has not been previously reported. We investigated the stability and catalytic activity for epoxidation reactions of a variety of alkenes with the tert-butyl hydroperoxide oxidant. In addition, we investigated the coordination between Mo and salen ligands and the possible mechanism of alkene epoxidation using this catalyst.

\section{Experimental}

\subsection{Materials}

Halloysite was obtained from Hebei, China. 3-Aminopropyltrimethoxysilane (APTMS) and [3-(2-aminoethyl)aminopropyl]trimethoxysilane (AAPTMS) were purchased from Alfa Aesar and used without further purification. Molybdenum trioxide, $N, N$-dimethylformamide (DMF), tert-butyl hydroperoxide (TBHP), and solvents were all analytical grade reagents purchased from Shanghai Chemical Reagent Co. Ltd. (Shanghai, China) and used without further purification. Deionized water was used for all of the experiments.

\subsection{Preparation of catalysts}

The HNTs-SL-Mo catalysts were prepared by a facile chemical surface modification and self-assembly method. APTMS $(0.5 \mathrm{~mL})$ and HNTs $(1 \mathrm{~g})$ were dispersed in toluene $(25 \mathrm{~mL})$. The system was vacuumized in the process of ultrasonic dispersion for $1 \mathrm{~h}$. Then, refluxing was performed at $110{ }^{\circ} \mathrm{C}$ for 24 $\mathrm{h}$ in a nitrogen environment. We obtained HNTs-APTMS after the solid was filtered out and dried under vacuum after washing with toluene several times. HNTs-APTMS (0.5 g) was dissolved in tepid ethanol $(40 \mathrm{~mL})$. Then, while stirring at $40{ }^{\circ} \mathrm{C}$, ethanol $(70 \mathrm{~mL})$ containing salicylaldehyde $(0.55 \mathrm{~mL})$ was added in $2 \mathrm{~h}$. This system was refluxed at $80{ }^{\circ} \mathrm{C}$ for $10 \mathrm{~h}$. After filtering, washing, and drying, we obtained a yellow solid, which was HNTs supporting salen ligands (HNTs-APTMS-SL). A mixture of HNTs-APTMS-SL (300 mg) and $\mathrm{MoO}\left(\mathrm{O}_{2}\right)_{2}(\mathrm{DMF})_{2}$ (30 mg) synthesized according to a procedure described in the literature $[37,38]$ was stirred in acetonitrile $(15 \mathrm{~mL})$ at room temperature for $48 \mathrm{~h}$. Afterwards, the solid was filtered out and dried under vacuum after washing with acetonitrile. This gave the HNTs-APTMS-Mo-SL catalyst.

The complete synthesis process of the catalyst is shown in

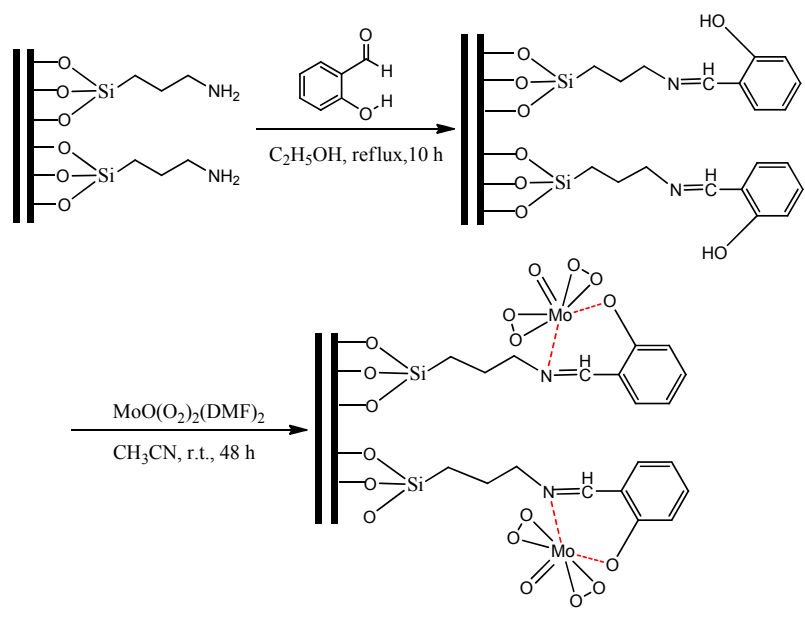

Fig. 1. Synthesis process and structure of the HNTs-APTMS-Mo-SL catalyst.

Fig. 1. We used AAPTMS instead of APTMS using the same method to obtain another catalyst, HNTs-AAPTMS-Mo-SL (Fig. 2(a)). The catalyst without the salen structure (HNTs-APTMSMo, Fig. 2(b)) was also prepared.

\subsection{Characterization of catalysts}

The size and morphology of the HNTs was observed by a Tecnai G2 F30 transmission electron microscope (TEM). The samples were obtained by placing a drop of a colloidal solution onto a copper grid and evaporating the solvent in air at room temperature. X-ray powder diffraction (XRD) patterns were obtained with a Shimadzu XRD-6000 diffractometer using $\mathrm{Cu}$ $K_{\alpha}$ radiation at $40 \mathrm{kV}$. Elemental analysis (EA) was carried out to analyze the elemental composition of the catalysts using an elemental analyzer (Vario EL, Elementar Analysensysteme $\mathrm{GmbH}$, Hanau, Germany). Fourier-transform infrared (FT-IR) spectra were recorded on an Impact 400 FT-IR spectrometer (Nicolet, Waltham, MA, USA), and the samples were measured with $\mathrm{KBr}$ pellets. X-ray photoelectron spectra (XPS) were recorded on a PHI-5702 photoelectron spectrometer, and the $\mathrm{C} 1 \mathrm{~s}$ line at $284.8 \mathrm{eV}$ was used as the binding energy reference. The Mo content was measured with an inductively coupled plasma-atomic emission spectrometer (ICP-AES).

\subsection{Catalytic epoxidation of alkenes by TBHP}

The epoxidation of alkenes was carried out using TBHP as (a)

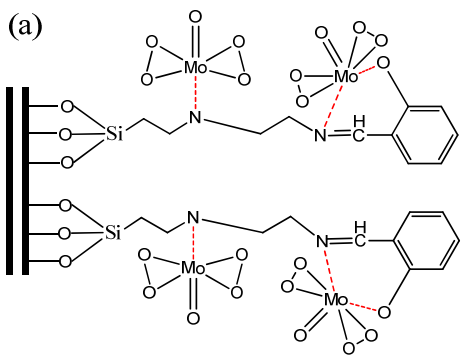

(b)

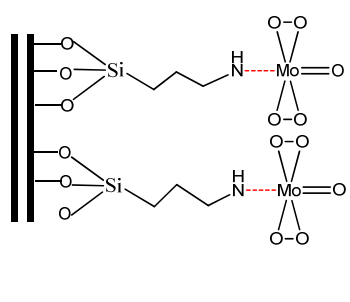

Fig. 2. Structure of HNTs-AAPTMS-Mo-SL (a) and HNTs-APTMS-Mo (b). 
an oxidizing agent. In a $25-\mathrm{mL}$ round bottom flask equipped with a magnetic stirrer bar, a mixture of alkene $(2.5 \mathrm{mmol})$, TBHP ( $5 \mathrm{mmol}$ ), catalyst ( $1 \mathrm{~mol} \% \mathrm{Mo}$ ), and solvent ( $8 \mathrm{~mL}$ ) was prepared and refluxed under stirring at different temperatures. After filtering off the catalyst, the filtrate was dehydrated and analyzed by a gas chromatograph-mass spectrometer (GC-MS, Agilent 7820A/5977E).

\section{Results and discussion}

\subsection{Synthesis of heterogeneous HNTs-supported Mo catalyst}

The structure and morphologies of the HNTs, HNTs-APTMSMo-SL, HNTs-AAPTMS-Mo-SL, and HNTs-APTMS-Mo were observed by TEM. Fig. 3(a) shows the TEM image of naturally occurring HNTs. The predominant form was a hollow tubular structure in the submicrometer range. The sizes of the inner and outer diameters of the halloysite tubules were about 15-20 and $40-50 \mathrm{~nm}$, respectively, depending on the deposit conditions. Characterization of HNTs-APTMS-Mo-SL by TEM is shown in Fig. 3(b). It shows that the Mo complex was completely attached to the modified HNTs, and there was no isolated Mo complex in the TEM image. Therefore, without any monodispersed Mo complex, it can be concluded that the Mo complex was distributed on the surface of the surface-modified HNTs. For comparison, the TEM images of HNTs-AAPTMS-MoSL and HNTs-APTMS-Mo are shown in Figs. 3(c) and 3(d). HNTs-AAPTMS-Mo-SL showed slight aggregation because of a mass of Mo complex and HNTs-APTMS-Mo showed less aggregation because of weak coordination between Mo and single $\mathrm{N}$ atoms.

The crystal structure and phase purity of the HNTs, HNTsAPTMS-SL, HNTs-APTMS-Mo-SL, and HNTs-APTMS-Mo were determined by XRD, as shown in Fig. 4. The positions and rela-


Fig. 3. TEM images of HNTs (a), HNTs-APTMS-Mo-SL (b), HNTsAAPTMS-Mo-SL (c), and HNTs-APTMS-Mo (d).

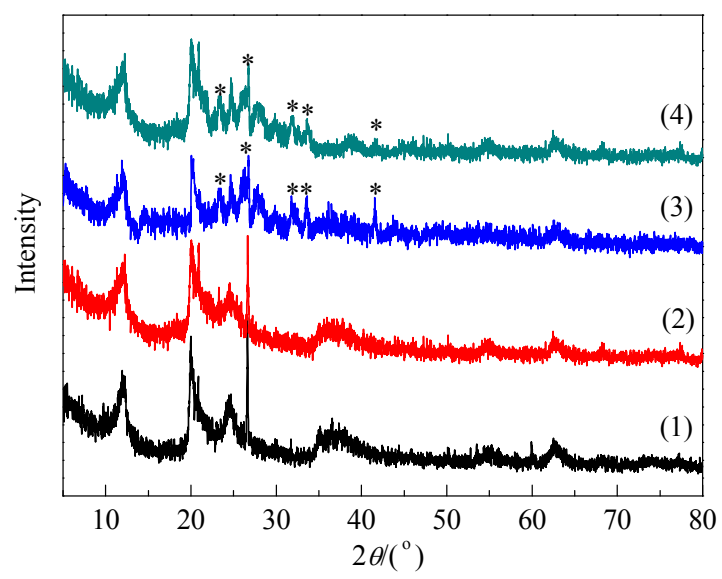

Fig. 4. XRD patterns of HNTs (1), HNTs-APTMS-SL (2), HNTs-APTMSSL-Mo (3), and HNTs-APTMS-Mo (4).

tive intensities of all the diffraction peaks of HNTs matched well with JCPDS 29-1487 [36,37]. The typical diffraction peaks of HNTs-APTMS-SL and HNTs-APTMS-Mo-SL were similar to those of the unfunctionalized HNTs. However, the intensities of the main peaks slightly decreased, which revealed that the crystal structure of the HNTs was well maintained after the introduction of organic functional groups. Some of the characteristic peaks decreased after immobilization of $\mathrm{MoO}\left(\mathrm{O}_{2}\right)_{2}(\mathrm{DMF})_{2}$. Furthermore, another five peaks over HNTsAPTMS-SL and HNTs-APTMS-Mo-SL (marked with asterisks) that can be attributed to the Mo(VI) species rather than $\mathrm{MoO}\left(\mathrm{O}_{2}\right)_{2}(\mathrm{DMF})_{2}$. This is evidence of the successful synthesis of the Mo salen structure. From the above results, HNTs-APTMSMo-SL was successfully synthesized. In addition, the peaks attributed to the Mo(VI) species of HNTs-APTMS-Mo were clearly smaller than those of HNTs-APTMS-Mo-SL, which might be because of the smaller amount of Mo (Table 2).

The FT-IR spectra of the samples are shown in Fig. 5. Two characteristic bands of HNTs at 3696 and $3621 \mathrm{~cm}^{-1}$ were present, which are due to the stretching vibration of $\mathrm{O}-\mathrm{H}$ in the inner-surface hydroxyl groups of $\mathrm{Al}-\mathrm{O}-\mathrm{H}$. The absorption peak at $910 \mathrm{~cm}^{-1}$ was ascribed to the deformation vibration of the above hydroxyl groups. Interlayer or adsorbed water is indicated by the stretching vibration at $3450 \mathrm{~cm}^{-1}$ and the corresponding deformation vibration at $1637 \mathrm{~cm}^{-1}$ [36,37]. Most of the absorption peaks of the catalysts did not change after modification, except for a decrease in the intensity of the $\mathrm{OH}$ stretching band. It was found that the basic structures of the HNTs and the functionalized HNTs were the same after modification and grafting between these groups and APTMS (or AAPTMS). The relatively high intensity of the band at 2933 $\mathrm{cm}^{-1}$ is characteristic of $-\mathrm{CH}_{2}$ stretching vibrations, which also indicated that APTMS (or AAPTMS) successfully bonded to the HNTs. Over HNTs-APTMS-SL, the bands at 1660 and $1251 \mathrm{~cm}^{-1}$ were induced by $\mathrm{C}=\mathrm{N}$ and $\mathrm{C}-\mathrm{O}$ stretching vibrations, which verified the successful synthesis of the salen ligand. It is worth noting that the $\mathrm{C}=\mathrm{N}$ and $\mathrm{C}-\mathrm{O}$ stretching vibrations in the spectra of HNTs-APTMS-Mo-SL and HNTs-AAPTMS-Mo-SL were similar to those of HNTs-APTMS-SL, indicating a strong inter- 


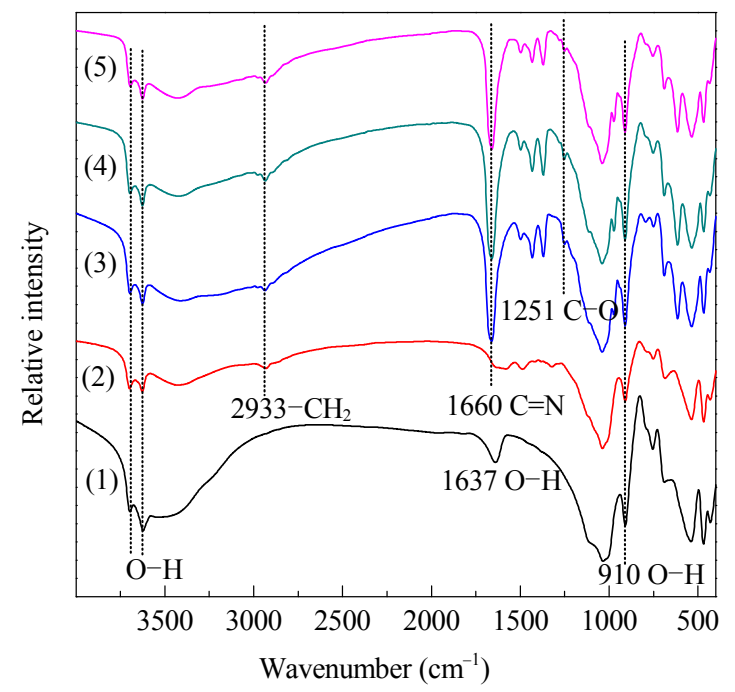

Fig. 5. FT-IR spectra of HNTs (1), HNTs-APTMS-Mo (2), HNTs-APTMSSL (3), HNTs-APTMS-Mo-SL (4), and HNTs-AAPTMS-Mo-SL (5).

action between Mo and the $\mathrm{ON}$ bidentate salen ligand. Therefore, FT-IR reasults confirmed the existence of the Mo salen structure by the post-treatment process.

In addition to XRD and FT-IR analysis, the XPS technique proved to be extremely useful to confirm the presence of APTMS and Mo, because they are sensitive to the surface and provide information not only about the electronic state of Mo, but also about the other atoms. As shown in Fig. 6, the peaks of Si $2 p, \mathrm{C} 1 s, \mathrm{~N} 1 s$, and $01 s$ appeared at standard positions. Moreover, the XPS analysis of Mo(VI) is shown in Fig. 6(a) and (b). As expected, the peaks at 237 and $403 \mathrm{eV}$ can be attributed to Mo $3 d$ and Mo $3 p$, which confirmed the existence of Mo(VI) with the same valence state as $\mathrm{Mo}$ in $\mathrm{MoO}\left(\mathrm{O}_{2}\right)_{2}(\mathrm{DMF})_{2}$ [38]. The XPS reasults provided evidence of the successful synthesis of the HNT-supported Mo catalyst.

In addition, EA was used to verify the presence of $\mathrm{C}, \mathrm{N}$, and H. As shown in Table 1, after the first step, APTMS and APPTMS were successfully attached to the HNTs because of the presence of the corresponding percentages of $\mathrm{C}, \mathrm{N}$, and H. Salicylaldehyde then reacted with the terminal amino group of HNTsAPTMS or HNTs-APPTMS to form the salen structure. The corresponding percentages of $\mathrm{C}, \mathrm{N}$, and $\mathrm{H}$ were detected in accordance with HNTs-APTMS-SL or HNTs-APPTMS-SL.
Table 1

Elemental analysis data of the catalysts.

\begin{tabular}{lccc}
\hline Catalyst & $\mathrm{C}(\%)$ & $\mathrm{N}(\%)$ & $\mathrm{H}(\%)$ \\
\hline HNTs-APTMS & 3.62 & 1.31 & 0.84 \\
HNTs-AAPTMS & 4.79 & 2.76 & 1.10 \\
HNTs-APTMS-SL & 9.27 & 1.23 & 1.02 \\
HNTs-AAPTMS-Mo-SL & 11.3 & 2.69 & 1.48 \\
\hline
\end{tabular}

\subsection{Catalytic epoxidation of alkenes using TBHP as an oxidant}

The catalytic activities of the three HNT-supported Mo catalysts and homogeneous Mo catalyst were initially investigated in the epoxidation of cyclohexene in the presence of TBHP. The catalytic activities of these four catalysts as well as PANI microsphere-Mo [38] and $\mathrm{MoO}_{x} / \mathrm{HAP}-\gamma-\mathrm{Fe}_{2} \mathrm{O}_{3}$ [11] are shown in Table 2. The same amount of Mo was used in the contrast tests. The turnover frequency (TOF) of HNTs-APTMS-Mo-SL was quite good $\left(23.75 \mathrm{~h}^{-1}\right)$, and twice that of $\mathrm{MoO}_{x} / \mathrm{HAP}-\gamma-\mathrm{Fe}_{2} \mathrm{O}_{3}$ $\left(10.94 \mathrm{~h}^{-1}\right)$. However, it was slightly less than that of PANI microsphere-Mo $\left(27.67 \mathrm{~h}^{-1}\right)$, which can be attributed to the higher reaction temperature $\left(60^{\circ} \mathrm{C}\right)$. Nevertheless, the conversion of cyclohexene catalyzed by the HNTs-APTMS-Mo-SL afforded 95\%, which is much higher than that obtained using the PANI microsphere-Mo (83\%) and $\mathrm{MoO}_{x} / \mathrm{HAP}-\gamma-\mathrm{Fe}_{2} \mathrm{O}_{3}(90.8 \%)$ catalysts despite their higher reaction temperatures. PANI microsphere-Mo does not have the Mo salen structure and only uses a $\mathrm{N}$ atom as a single ligand coordinated to $\mathrm{MoO}\left(\mathrm{O}_{2}\right)(\mathrm{DMF})_{2}$. The active site of $\mathrm{MoO}_{x} / \mathrm{HAP}-\gamma-\mathrm{Fe}_{2} \mathrm{O}_{3}$ is the Mo oxide. Therefore, it can be assumed that the Mo salen structure is conducive to improving the conversion and efficiency of alkene epoxidation. On the other hand, by comparing the conversion of the epoxidation reaction catalyzed by HNTs-APTMS-Mo-SL (95\%), HNTs-APTMS-Mo (87\%) without the salen structure, and HNTs-APPTMS-Mo-SL (90\%), which has both Mo salen and Mo coordinated to one $\mathrm{N}$ atom, it is suggested that the Mo salen structure of the catalysts played an important role in this reaction. $\mathrm{MoO}\left(\mathrm{O}_{2}\right)$ connected to the salen structure probably had a unique mechanism that was the most efficient catalytic mechanism for epoxidation of alkenes with the TBHP oxidant. According to the reported mechanism [39], the possible epoxidation process catalyzed by the Mo salen catalyst is illustrated in Scheme 1. Heterogeneous $\mathrm{MoO}\left(\mathrm{O}_{2}\right)(\mathrm{DMF})_{2}$ had a lower catalytic activity (73\%) than supported Mo. When the reaction time
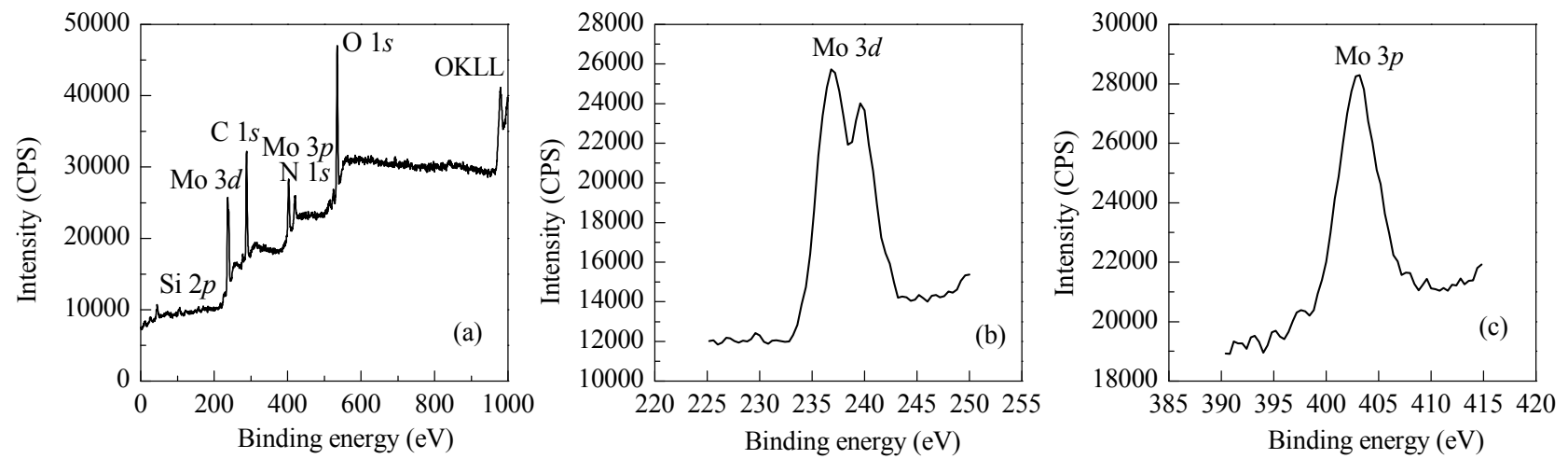

Fig. 6. XPS spectrum of HNTs-APTMS-Mo-SL (a) and the specific Mo XPS spectra of HNTs-APTMS-Mo-SL (b, c). 
Table 2

Epoxidation of cyclohexene to the corresponding epoxide with TBHP using different catalysts.

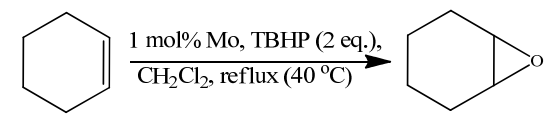

\begin{tabular}{|c|c|c|c|c|c|c|}
\hline Catalyst & Amount (mg) & Mo (\%) & Time (h) & Conversion (\%) & Selectivity (\%) & TOF a $\left(\mathrm{h}^{-1}\right)$ \\
\hline HNTs-APTMS-Mo-SL & 61 & 4.11 & 4 & 95 & 96 & 23.75 \\
\hline HNTs-AAPTMS-Mo-SL & 50 & 4.98 & 4 & 90 & 95 & 22.50 \\
\hline HNTs-APTMS-Mo & 94 & 2.63 & 4 & 87 & 96 & 21.75 \\
\hline $\mathrm{MoO}\left(\mathrm{O}_{2}\right)_{2}(\mathrm{DMF})_{2}$ & 9 & 28.90 & 4 & 73 & 94 & 18.25 \\
\hline $\mathrm{MoO}\left(\mathrm{O}_{2}\right)_{2}(\mathrm{DMF})_{2}$ & 9 & 28.90 & 8 & 74 & 97 & 9.25 \\
\hline $\mathrm{MoO}\left(\mathrm{O}_{2}\right)_{2}(\mathrm{DMF})_{2}$ & 9 & 28.90 & 12 & 76 & 95 & 6.33 \\
\hline PANI microsphere-Mo ${ }^{b}$ & 120 & 7.35 & 6 & 83 & 97 & 27.67 \\
\hline $\mathrm{MoO}_{x} / \mathrm{HAP}-\gamma-\mathrm{Fe}_{2} \mathrm{O}_{3}{ }^{\mathrm{c}}$ & 25 & 20 & 8 & 90.8 & 98.7 & 10.94 \\
\hline
\end{tabular}

a Turnover frequency, i.e., moles of cyclohexene converted per mole of Mo per hour.

${ }^{b}$ Ref. [38]. Reaction conditions: cyclohexene (1.84 mL), TBHP $(4.8 \mathrm{~mL}), \mathrm{CHCl}_{3}(8 \mathrm{~mL}), 60^{\circ} \mathrm{C}$.

${ }^{c}$ Ref. [11]. Reaction conditions: cyclohexene (5 mmol), TBHP (5 mmol), $\mathrm{CHCl}_{3}(8 \mathrm{~mL}), 70^{\circ} \mathrm{C}$.

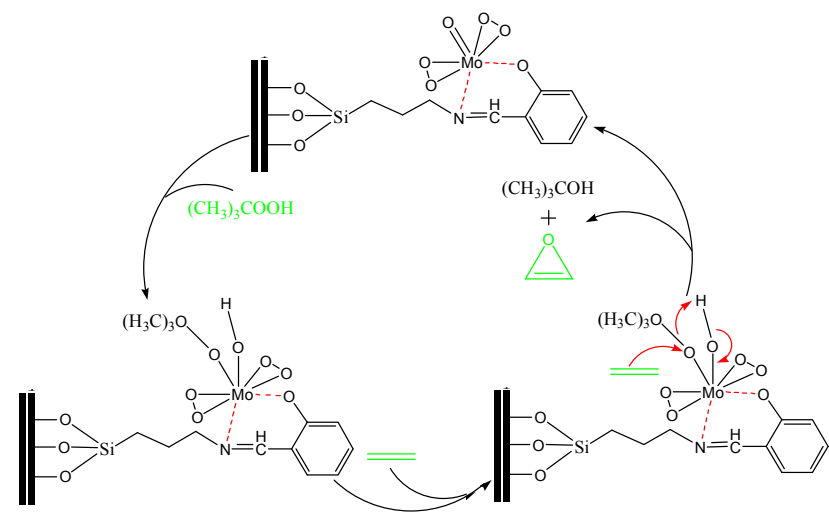

Scheme 1. Epoxidation process catalyzed by HNTs-APTMS-Mo-SL.

was extended to $12 \mathrm{~h}$, conversion slightly increased to $76 \%$. The reaction catalyzed by HNTs-APTMS-Mo had higher conversion with lower temperature and shorter reaction time than that reported for the PANI microsphere-Mo catalyst. Hence, supported $\mathrm{MoO}\left(\mathrm{O}_{2}\right)(\mathrm{DMF})_{2}$ is an excellent catalyst for alkene epoxidation reaction. Among the catalysts investigated, the HNT-supported Mo catalysts coordinated with ligands showed the best catalytic activity, and HNT-supported Mo salen was the best catalyst.

Table 3

Epoxidation of various alkenes with TBHP catalyzed by HNTs-APTMSMo-SL.

\begin{tabular}{|c|c|c|c|c|c|c|c|}
\hline Entry & Alkene & $t / \mathrm{h}$ & Solvent & $\mathrm{T} /{ }^{\circ} \mathrm{C}$ & $\begin{array}{c}\text { Con- } \\
\text { version } \\
(\%)\end{array}$ & $\begin{array}{c}\text { Selec- } \\
\text { tivity } \\
(\%)\end{array}$ & $\begin{array}{c}\text { TOF } \\
\left(\mathrm{h}^{-1}\right)\end{array}$ \\
\hline 1 & & 4 & $\mathrm{CH}_{2} \mathrm{Cl}_{2}$ & 40 & 95 & 96 & 23.75 \\
\hline 2 & & 4 & $\mathrm{CH}_{2} \mathrm{Cl}_{2}$ & 40 & $>99$ & 98 & 25.0 \\
\hline 3 & & 6 & $\mathrm{CH}_{3} \mathrm{CN}$ & 80 & 87 & 90 & 14.50 \\
\hline 4 & & 6 & $\mathrm{CH}_{3} \mathrm{CN}$ & 80 & 89 & 91 & 14.83 \\
\hline 5 & & 6 & $\mathrm{CH}_{3} \mathrm{CN}$ & 80 & 83 & 90 & 13.83 \\
\hline 6 & & 8 & $\mathrm{CH}_{3} \mathrm{CN}$ & 80 & 80 & 93 & 10.0 \\
\hline 7 & & 12 & toluene & 110 & 91 & 99 & 7.58 \\
\hline
\end{tabular}

Reaction conditions: alkene (2.5 mmol), TBHP (5 mmol), HNTs-APTMSMo-SL (60 mg), solvent ( $8 \mathrm{~mL}$ ).
Table 3 shows the catalytic activity of HNTs-APTMS-Mo-SL used for the epoxidation of a wide range of alkenes. It was found that this catalyst efficiently converted cyclic, linear, and aromatic alkenes to their corresponding epoxides. It showed that carbocyclic alkenes were efficiently converted to the corresponding epoxides with high conversion and TOF (Table 3, entries 1 and 2). However, oxidation of aromatic and linear alkenes required longer reaction times and higher reaction temperature than carbocyclic alkenes (entries 3-7).

Experiments were conducted to test the cycle performance and the stability of the catalyst. As shown in Fig. 7, the HNTs-APTMS-Mo-SL catalyst could be filtered and reused at least eight times without significant loss of activity (Fig. 7(a)). To investigate the stability of the Mo salen structure, the catalytic performance of the separated liquids was tested by adding fresh cyclohexene and TBHP into the filtrates after each run. Epoxidation reactions under the same reaction conditions gave the same results as the blank experiment. The performance of the HNTs-APTMS-Mo catalysts decreased during the reuse experiments (Fig. 7(b)). A total of $0.67 \mathrm{mg}$ Mo (27\% of the original Mo amount) was detected by ICP in the separated liquid after the eighth cycle, which explained the sharp decrease in catalytic activity. However, the separated liquid after the eighth cycle catalyzed by HNTs-APTMS-Mo-SL contained $0.09 \mathrm{mg}$ Mo (3.6\% of the original Mo amount). The experiments demonstrated the excellent stability of the Mo salen structure.

\section{Conclusions}

A robust, highly effective, and reusable HNTs-Mo-SL catalyst was successfully synthesized, characterized, and used for the epoxidation of cyclooctene using the TBHP oxidant. This supported heterogeneous catalyst was found to be highly effective for the epoxidation of a wide range of alkenes, including linear, cyclic, and aromatic alkenes. The HNTs-Mo-SL catalyst exhibited a higher activity than homogeneous Mo and supported Mo without the salen structure (HNTs-APTMS-Mo). It was found that the salen structure played an important role in immobilizing $\mathrm{MoO}\left(\mathrm{O}_{2}\right)_{2}(\mathrm{DMF})_{2}$ and improving the conversion and efficiency of alkene epoxidation, which cannot be obtained using 

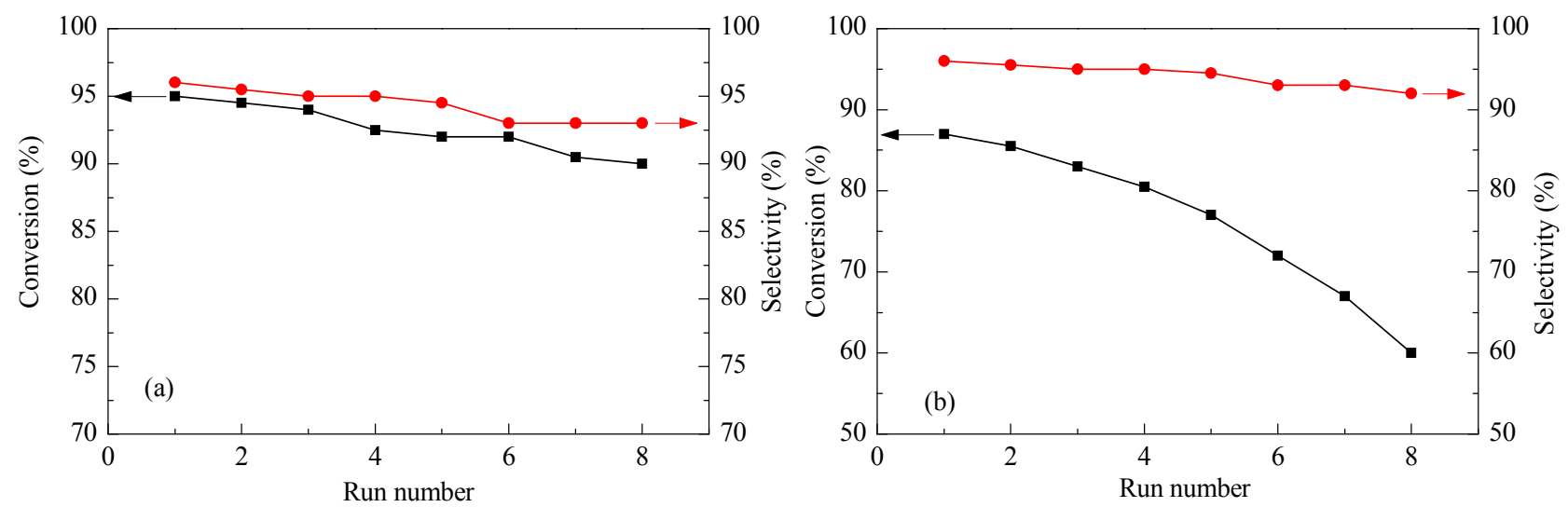

Fig. 7. Catalyst reusability for HNTs-APTMS-Mo-SL (a) and HNTs-APTMS-Mo (b). Reaction conditions: cyclohexene (2.5 mmol), TBHP (5 mmol), HNTs-APTMS-Mo-SL (60 mg), HNTs-APTMS-Mo ( $95 \mathrm{mg}$ ), solvent $(8 \mathrm{~mL}), 40^{\circ} \mathrm{C}$.

other ligands, such as the $\mathrm{N}$ atom as a single ligand. Furthermore, the coordination between Mo and the salen ligand and the possible mechanism of alkene epoxidation catalyzed by this catalyst were investigated. Moreover, the catalyst had excellent stability and could be easily recycled in the reaction system. Given that halloysite nanotubes are cheap and easy to obtain, this catalyst offers a novel alternative for the rational design of catalysts with desired features.

\section{Acknowledgments}

The authors are grateful to the Key Laboratory of Nonferrous Metals Chemistry and Resources Utilization, Gansu Province for financial support.

\section{References}

[1] Lane B S, Burgess K. Chem Rev, 2003, 103: 2457

[2] Joergensen K A. Chem Rev, 1989, 89: 431

[3] Zou X C, Shi K Y, Wang C. Chin J Catal (邹晓川, 石开云, 王存. 催化 学报), 2014, 35: 1446
[4] Qi B, Lu X H, Fang S Y, Lei J, Dong Y L, Zhou D, Xia Q H.J Mol Catal A, 2011, 334: 44

[5] Xu G, Xia Q H, Lu X H, Zhang Q Zhan H J. J Mol Catal A, 2007, 266: 180

[6] Calvente R M, Campos-Martin J M, Fierro J L G. Catal Commun, 2002, 3: 247

[7] Thiel W R. J Mol Catal A, 1997, 117: 449

[8] Bakala P C, Briot E, Salles L, Brégeault J M. Appl Catal A, 2006, 300: 91

[9] Jarupatrakorn J, Coles M P, Tilley T D. Chem Mater, 2005, 17: 1818

[10] Wang G, Feng L S, Luck R L, Evans D G, Wang Z Q, Duan X. J Mol Catal A, 2005, 241: 8

[11] Yuan C Y, Zhang Y, Chen J. Chin J Catal (袁程远, 张妍, 陈静. 催化 学报), 2011, 32: 1166

[12] Tangestaninejad S, Moghadam M, Mirkhani V, MohammadpoorBaltork I, Ghani K. Inorg Chem Commun, 2008, 11: 270

[13] Bruno S M, Fernandes J A, Martins L S, Gonçalves I S, Pillinger M, Ribeiro-Claro P, Rocha J, Valente A A. Catal Today, 2006, 114: 263

[14] Zhu H Y, Zhang Y, Zhou D G, Guan J, Bao X H. Chin J Catal (朱洪元, 张元, 周丹红, 关静, 包信和. 催化学报), 2007, 28: 180

[15] Sakthivel A, Zhao J, Raudaschl-Sieber G, Hanzlik M, Chiang A S T, Kühn F E. Appl Catal A, 2005, 281: 267

\section{Graphical Abstract}

Chin. J. Catal., 2015, 36: 348-354 doi: 10.1016/S1872-2067(14)60244-8

Epoxidation of alkenes efficiently catalyzed by Mo salen supported on surface-modified halloysite nanotubes

Yu Long, Bing Yuan, Jiantai Ma*

Lanzhou University

Halloysite-nanotube-supported molybdenum salen catalysts were successfully prepared by facile chemical surface modification, and they were stable and showed excellent catalytic activity for the epoxidation of alkenes.

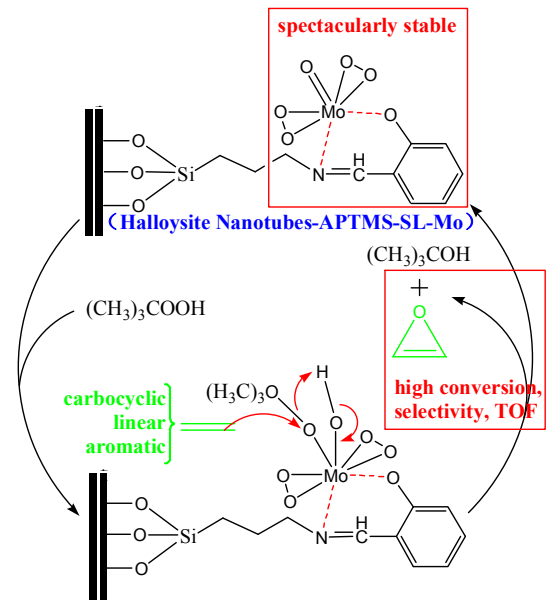


[16] Jia M J, Seifert A, Thiel W R. Chem Mater, 2003, 15: 2174

[17] Xing S Y, Zhou D H, Cao L, Li X. Chin J Catal (邢双英, 周丹红, 曹亮, 李新. 催化学报), 2010, 31: 415

[18] Sakthivel A, Zhao J, Kühn F E. Catal Lett, 2005, 102: 115

[19] MoghadamM, Tangestaninejad S, Mirkhani V, MohammadpoorBaltork I, Mirbagheri N S. J Organomet Chem, 2010, 695: 2014

[20] Moghadam M, Tangestaninejad S, Mirkhani V, MohammadpoorBaltork I, Mirjafari A, Mirbagheria N S. J Mol Catal A, 2010, 329: 44

[21] Beall G W, Sowersby D S, Roberts R D, Robson M H, Lewis L K. Biomacromolecules, 2009, 10: 105

[22] Shamsi M H, Geckeler K E. Nanotechnology, 2008, 19: 075604

[23] Hirano Y, Miura Y F, Sugi M, Ishii T. Colloids Surf A, 2002, 198-200: 37

[24] Yah W O, Xu H, Soejima H, Ma W, Lvov Y, Takahara A. J Am Chem Soc, 2012, 134: 12134

[25] Yao Y, Chaubey G S, Wiley J B. J Am Chem Soc, 2012, 134: 2450

[26] Abdullayev E, Joshi A, Wei W B, Zhao Y F, Lvov Y. ACS Nano, 2012, 6: 7216

[27] Islam M R, Bach L G, Lim K T. Appl Surf Sci, 2013, 276: 298

[28] Shchukin D G, Lamaka S V, Yasakau K A, Zheludkevich M L, Fer- reira M G S, Möhwald H.J Phys Chem C, 2008, 112: 958

[29] Ranganatha S, Venkatesha T V, Vathsala K. Appl Surf Sci, 2012, 263: 149

[30] Fix D, Andreeva D V, Lvov Y M, Shchukin D G, Möhwald H. Adv Funct Mater, 2009, 19: 1720

[31] Shchukin D G, Sukhorukov G B, Price R R, Lvov Y M. Small, 2005, 1: 510

[32] Wan C Y, Li M, Bai X, Zhang Y.J Phys Chem C, 2009, 113: 16238

[33] Jiang J Q Zhang Y W, Yan L W, Jiang P K. Appl Surf Sci, 2012, 258: 6637

[34] Pan J M, Wang B, Dai J D, Dai X H, Hang H, Ou H X, Yan Y S. J Mater Chem, 2012, 22: 3360

[35] Wang L, Chen J L, Ge L, Zhu Z H, Rudolph V. Energy Fuels, 2011, 25: 3408

[36] Wang R J, Jiang G H, Ding Y W, Wang Y, Sun X K, Wang X H, Chen W X. ACS Appl Mater Interfaces, 2011, 3: 4154

[37] Mimoun H, de Roch I S, Sajus L. Bull Soc Chim France, 1969: 1481

[38] Ding H J, Wang G, Yang M, Luan Y, Wang Y N, Yao X X.J Mol Catal A, 2009, 308: 25

[39] Masteri-Farahani M.J Mol Catal A, 2010, 316: 45

\title{
埃洛石表面修饰并负载salen钼高效催化烯烃环氧化反应
}

\author{
龙 雨, 袁 冰, 马建泰 ${ }^{*}$ \\ 兰州大学化学化工学院, 功能有机分子化学国家重点实验室, 甘肃兰州730000
}

摘要: 采用温和的化学表面改性和自组装方法成功制备了埃洛石纳米管负载salen钿(HNTs-SL-Mo)催化剂, 运用透射电镜、X射线 衍射、红外光谱、诱导偶合等离子体谱和X射线光电子能谱表征了催化剂的形态、大小和分散性等性质. 结果证明了 salen结构的 存在和埃洛石配位锄催化剂的成功制备. 制备的催化剂在各种烯烃的环氧化反应中均有很好的活性, 且活性高于均相催化剂. 对 比实验表明, 在固定 $\mathrm{MoO}\left(\mathrm{O}_{2}\right)_{2}(\mathrm{DMF})_{2}$ 时, salen结构发挥了重要作用, 不能用 $\mathrm{N}$ 原子作为单一配体来代替. 本文还推测了钼和 salen 配体可能的连接方式和该催化剂催化烯烃环氧化反应的机理. 该催化剂在重复使用 8 次后其活性未见明显下降, 表现出优异的重 复使用性能. 由于埃洛石是一种廉价易得的材料, 因此它可为设计效果独特的催化剂提供一个选择.

关键词: Salen钼; 烯烃环氧化; 管状埃洛石; 表面修饰; 高效催化剂

收稿日期: 2014-09-13. 接受日期: 2014-11-03. 出版日期: 2015-03-20.

*通讯联系人. 电话：(0931)8912577; 传真: (0931)8912882; 电子信箱: majiantai@lzu.edu.cn

本文的英文电子版由Elsevier出版社在ScienceDirect上出版(http://www.sciencedirect.com/science/journal/18722067). 